\title{
A systemic ultrasound positioning protocol for nasointestinal tube in critically ill patients
}

\author{
Ruizhong Ye ${ }^{1 \dagger}$, Xuping Cheng ${ }^{2 \dagger}$, Huihui Chai ${ }^{3^{*}}$, Chengzhong Peng ${ }^{1}$, Jingquan Liu ${ }^{4}$ and Jiyong Jing ${ }^{5^{*}}$ (D)
}

\section{Dear Editor,}

Critically ill patients have a high nutritional risk for a variety of reasons such as insufficient nutrient intake, and increased nutrient loss. Malnutrition readily impairs organ and immune function, increasing the risk of infection and mortality. Many clinical practice guidelines recommend enteral nutrition (EN) for patients within 24 to $48 \mathrm{~h}$ of entering the intensive care unit (ICU) [1, 2]. Patients unsuitable for EN by nasogastric tube, need to be provided with post-pyloric feeding. EN through nasointestinal tube (NIT) is the preferred choice, as it can effectively avoid aspiration caused by reflux, and enhance feeding tolerance. Hence, quick and accurate NIT postpylorus placement and positioning are crucial [2].

The commonly used methods for aiding placement and positioning of NITs, include abdominal X-ray, auscultation, observation of aspirated fluid, measuring $\mathrm{pH}$, and use of electromagnetic devices and integrated real-time imaging systems. However, these methods have shortcomings, including a lack of visualization, exposure to ionizing radiation, image overlap, or are not readily available, which can lead to subjective placement, low positioning accuracy, and additional costs [3, 4]. Ultrasonography has attracted attention owing to its ready availability, safety, ease of visualization, threedimensional spatial view, lack of additional cost, and the

\footnotetext{
*Correspondence: 18895687926@163.com; jiyong_jing@126.com

${ }^{\dagger}$ Ruizhong Ye and Xuping Cheng contributed equally to the article and

should be considered co-first authors

${ }^{3}$ Graduate Department, Bengbu Medical College, No. 2600, Donghai

Avenue, Bengbu 233000, Anhui, China

${ }^{5}$ Department of Medical Education and Simulation Center, Zhejiang

Provincial People's Hospital, Affiliated People's Hospital, Hangzhou

Medical College, Hangzhou 310014, Zhejiang, China

Full list of author information is available at the end of the article
}

availability of new techniques such as contrast-enhanced ultrasound [5]. Ultrasonography has been used for rapid positioning of feeding tubes in COVID-19 patients, which reduces the risk of virus transmission [6].

With the new ultrasonic techniques and methods applied in NIT positioning, requirements for the sonographer (e.g., detailed knowledge of anatomy) and the ultrasound equipment (e.g., an ultrasound contrast function) have also increased. The isolated use of each method or technique can necessitate repeated examinations and take increased time. Having a systemic ultrasound positioning method is important for the promotion and application of ultrasonography.

Based on these considerations, we established a systemic ultrasound positioning protocol (Fig. 1) for NIT placement in critically ill patients, based on research as follows [5]: (1) Four critical anatomical parts, the cervical esophagus, pylorus, duodenal bulb, and horizontal part of the duodenum, were determined. Their ultrasound views were standardized. (2) The duodenal bulb was located by identifying the gallbladder and head of the pancreas. The horizontal part of the duodenum was located by identifying the abdominal aorta, inferior vena cava, and mesenteric vessels. The latter was determined as the part for a prioritized examination for its less time-consuming. (3) The number of cross-sections of the NIT in the short-axis view of the pylorus helps to confirm whether it is placed post-pylorus. An odd number indicates an anterior or post-pylorus tube placement, which needs to be considered with the NIT insertion depth. An even number indicates anterior pyloric placement. (4) New acoustic signs of the NIT (Fig. 2) and the use of new techniques effectively improve the imaging effect of the tube. Abdominal X-ray was used as the gold standard in

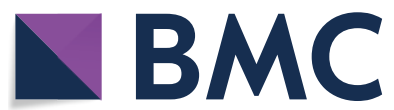

(c) The Author(s) 2021. This article is licensed under a Creative Commons Attribution 4.0 International License, which permits use, sharing, adaptation, distribution and reproduction in any medium or format, as long as you give appropriate credit to the original author(s) and the source, provide a link to the Creative Commons licence, and indicate if changes were made. The images or other third party material in this article are included in the article's Creative Commons licence, unless indicated otherwise in a credit line to the material. If material is not included in the article's Creative Commons licence and your intended use is not permitted by statutory regulation or exceeds the permitted use, you will need to obtain permission directly from the copyright holder. To view a copy of this licence, visit http://creativecommons.org/licenses/by/4.0/. The Creative Commons Public Domain Dedication waiver (http://creativecommons.org/publicdomain/zero/1.0/) applies to the data made available in this article, unless otherwise stated in a credit line to the data. 


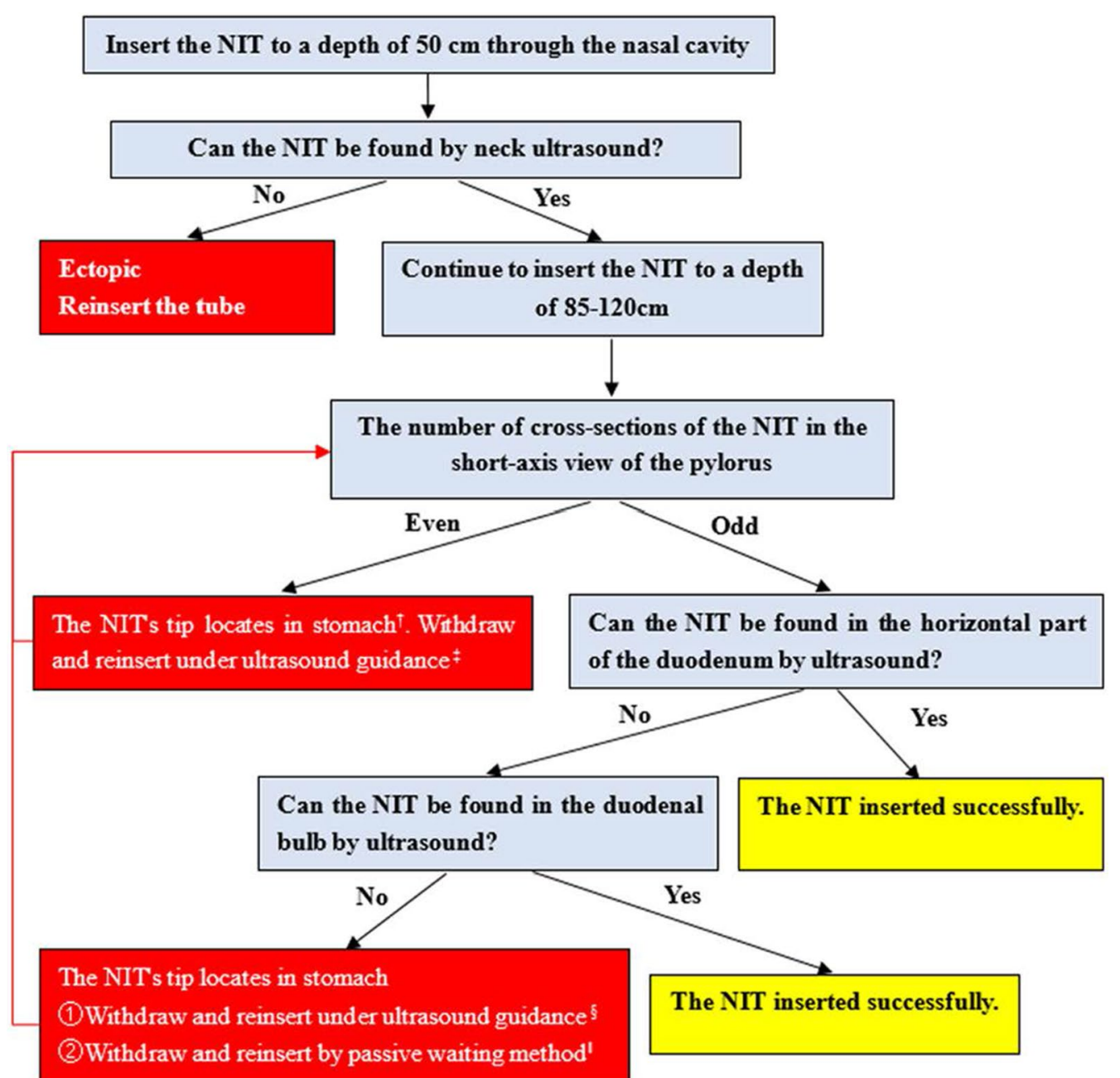

Fig. 1 Illustration of the systemic ultrasound protocol for positioning nasointestinal tubes (NITs) in critically ill patients. ${ }^{\dagger}$ There are two situations: (1) The NIT coils in the stomach cavity; (2) The NIT turns back post-pylorus, with the tip locating in the stomach cavity. ${ }^{*}$ Based on these two situations, different methods are adopted, as follows: (1) When the NIT coils in the stomach cavity, it should be withdrawn to a depth of about $50 \mathrm{~cm}$ and then reinserted under ultrasound guidance. (2) When the NIT turns back post-pylorus, it should be withdrawn to a depth of about $75 \mathrm{~cm}$ (the tip roughly located in the pylorus) and then reinserted it under ultrasound guidance. ${ }^{5}$ The NIT is withdrawn to a depth of about $50 \mathrm{~cm}$ and then reinserted under ultrasound guidance. "If there is a recurrent failure of NIT insertion under ultrasound guidance, adopt a passive waiting method, and allow the NIT to be guided through the pylorus using gastrointestinal peristalsis

our study of 157 patients. The performance indicators for post-pyloric NIT positioning of this protocol were $96.4 \%$, $90.0 \%, 98.5 \%, 78.3 \%, 95.5 \%$, and 0.81 , for the sensitivity, specificity, positive predictive value, negative predictive value, accuracy, and the kappa coefficient, respectively. The median examination time was $20 \mathrm{~s}$ [15-33].
NIT positioning can be rapidly and accurately performed using this protocol, helping critically ill patients achieve early EN. There were some limitations in this study. It was a single-center study and patients with abnormal anatomy of the digestive tract(e.g., genetic variation or gastrectomy) were excluded. A multicenter study

(See figure on next page.)

Fig. 2 Acoustic signs of the nasointestinal tube (NIT) on ultrasound. a Double-track sign: white arrows; b Five lines sign: red dotted box; Guidewire: yellow arrows; Wall of the NIT: white arrows; c Bar shadow sign: white arrows; NIT: yellow arrow; d: Bright band sign: white arrows; e Gas bead-like sign: white arrows; NIT: yellow arrow; f: Dynamic water flow sign: white arrows; g: Short-axis acoustic shadow sign: white arrows. NIT: yellow arrow. $\mathrm{DB}$, duodenal bulb; GB, gallbladder; LL, left liver; PH, pancreatic head; PY, pylorus 

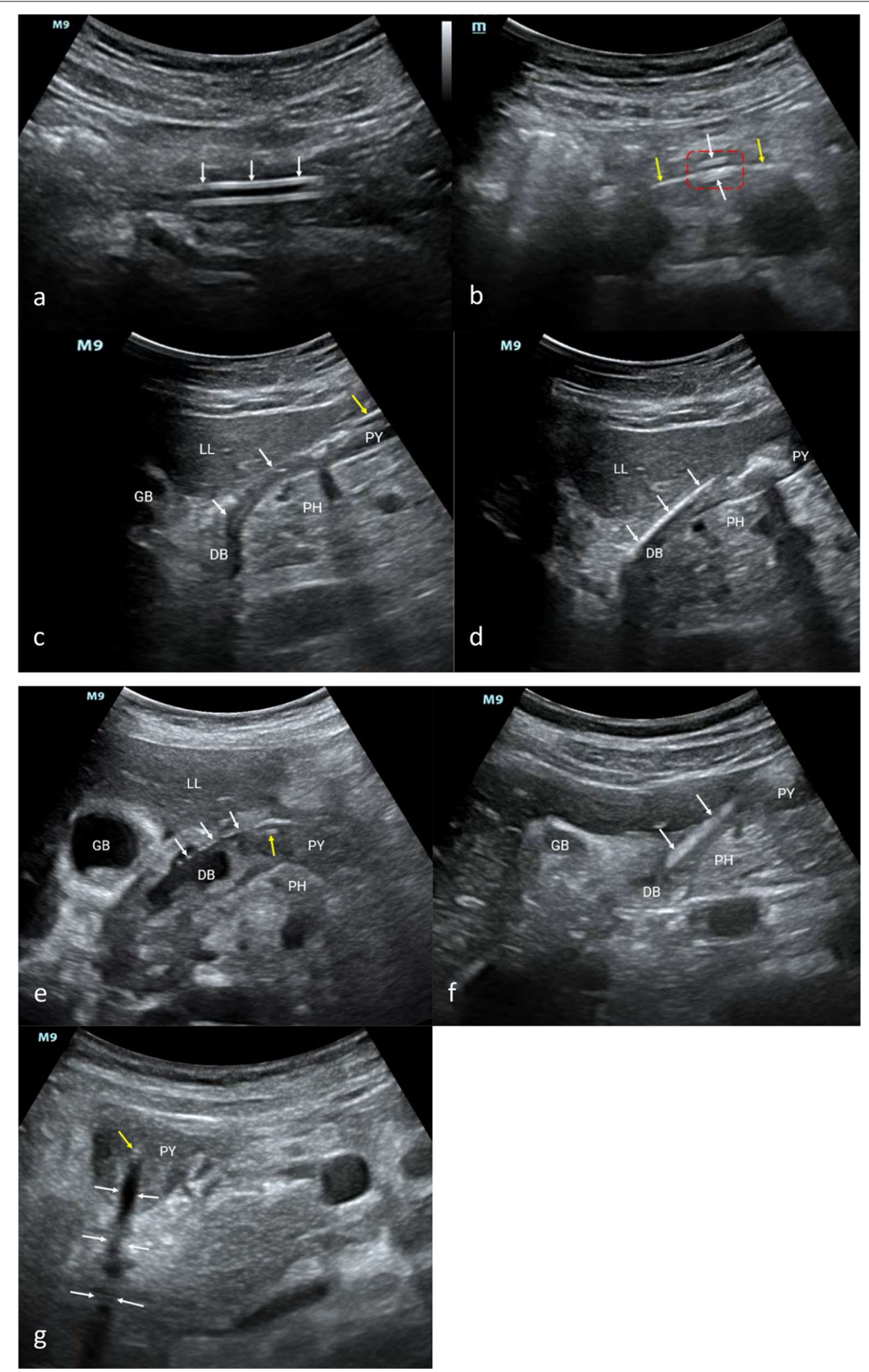
with a large sample size is required to verify the feasibility of using this protocol. A comparative study on the effect of sonographer proficiency on the accuracy of NIT positioning is also necessary.

\section{Acknowledgements}

We are grateful to Renhua Sun, MD, Xianghong Yang, MD, and Xiaoming Fan, MD, for their guidance and advice during the study's implementation process study. We would like to express our appreciation to all doctors and other hospital staff for their efforts in this study. We are grateful to all patients for participating.

\section{Authors' contributions}

J.J., H.C., C.P., R.Y., and X.C. undertook study design; H.C., R.Y., and J.L. enrolled patients and acquired data; R.Y, X.C, H.C., C.P., J.J., and J.L. drafted the manuscript and revised it critically. All authors read and approved the final manuscript.

\section{Funding}

This work was supported by the General Research Project of Department of Education of Zhejiang Province (grant number:Y202044583, to Dr. Ye), Zhejiang Medicine Scientific and Technology Project (grant number: 2021KY026, to Dr.Ye), and Zhejiang Medicine Scientific and Technology Project(2020KY021, to Dr. Jing).

\section{Availability of data and materials}

Some or all datasets generated and/or analyzed during the current study are not publicly available but are available from the corresponding author on reasonable request.

\section{Declarations}

\section{Ethics approval and consent to participate}

Written informed consent was obtained from all patients or their next of kin. The Institutional Ethical Review Board of the Zhejiang Provincial People's Hospital approved the study protocols and consent forms.

\section{Consent for publication}

Not applicable.

\section{Competing interests}

All authors declare that there is no conflict of interest to report.

\section{Author details}

${ }^{1}$ Department of Ultrasound Medicine, Zhejiang Provincial People's Hospital, Affiliated People's Hospital, Hangzhou Medical College, Hangzhou 310014,
Zhejiang, China. ${ }^{2}$ Department of Intensive Care, Dongyang People Hospital, Jinhua 322100, Zhejiang, China. ${ }^{3}$ Graduate Department, Bengbu Medical College, No. 2600, Donghai Avenue, Bengbu 233000, Anhui, China. ${ }^{4}$ Department of Intensive Care, Zhejiang Provincial People's Hospital, Affiliated People's Hospital, Hangzhou Medical College, Hangzhou 310014, Zhejiang, China. ${ }^{5}$ Department of Medical Education and Simulation Center, Zhejiang Provincial People's Hospital, Affiliated People's Hospital, Hangzhou Medical College, Hangzhou 310014, Zhejiang, China.

Received: 9 April 2021 Accepted: 12 June 2021

Published online: 19 June 2021

\section{References}

1. Reintam Blaser A, Starkopf J, Alhazzani W, Berger MM, Casaer MP, Deane AM, et al. Early enteral nutrition in critically ill patients: ESICM clinical practice guidelines. Intensive Care Med. 2017;43(3):380-98. https://doi.org/10. 1007/s00134-016-4665-0.

2. Sun RH, Jiang RL, Huang M, Cai GL. Consensus of early enteral nutrition clinical practice in critically ill patients. Chin Crit Care Med. 2018;30(8):715-21. https://doi.org/10.3760/cma.j.issn.2095-4352.2018.08. 001.

3. Bourgault AM, Powers J, Aguirre L, Hines R. Migration of feeding tubes assessed by using an electromagnetic device: a cohort study. Am J Crit Care. 2020;29(6):439-47. https://doi.org/10.4037/ajcc2020744.

4. Boullata Jl, Carrera AL, Harvey L, Escuro AA, Hudson L, Mays A, et al. (2017) ASPEN safe practices for enteral nutrition therapy. J Parenter Enteral Nutr 41(1):15-103.

5. Ye RZ, Yang XH, Feng ZW, Hu BC, Liu JQ, LvZQ, et al. Application of hybrid contrast-enhanced ultrasound imaging technology in positioning indwelling nasointestinal tube in critically ill patients. Chin J Med Ultras. 2019;16(2):87-94. https://doi.org/10.3877/cma.j.issn.1672-6448.2019.02. 003.

6. Qian A, Xu S, Lu X, Tang L, Zhang M, Chen X. Rapid positioning of nasogastric tube by ultrasound in COVID-19 patients. Crit Care. 2020;24(1):568. https://doi.org/10.1186/s13054-020-03285-8.

\section{Publisher's Note}

Springer Nature remains neutral with regard to jurisdictional claims in published maps and institutional affiliations.

Ready to submit your research? Choose BMC and benefit from:

- fast, convenient online submission

- thorough peer review by experienced researchers in your field

- rapid publication on acceptance

- support for research data, including large and complex data types

- gold Open Access which fosters wider collaboration and increased citations

- maximum visibility for your research: over 100M website views per year

At BMC, research is always in progress.

Learn more biomedcentral.com/submissions 